\title{
Foster and adoptive mothers' assessment of permanent family placements
}

\author{
Joy S Holloway
}

\begin{abstract}
Objectives-To obtain the new carers' evaluation of the success of permanent placement of children within their families and any special needs in the children, and to determine the adequacy of support after placement.

Design-A postal questionnaire was sent to the foster or adoptive mothers of a five year cohort of 234 children placed for permanence, three to eight years previously, by one local authority.

Setting-Newcastle upon Tyne Social Services Adoption and Fostering Unit.

Subjects-All 234 permanent family placements recommended by the family placement panel from 1 January 1986 to 31 December 1990.

Main outcome measure-The adoptive or foster mothers' evaluation of the placement.

Results-There was a 54\% response rate, but the respondents did not differ significantly from the non-respondents in the variables tested. Only $33 \%$ of the children were placed when less than 2 years old with no special needs. Twenty per cent of the school age children had statements of special educational needs at placement. Ninety seven per cent of infant placements were rated 'very successful' for the child by the new mothers, as were $90 \%$ of 1-6 year olds, but only $31 \%$ of children who were placed when older than 6 years were rated in this way. A third of the adoptive and foster mothers had experienced major difficulties in the placement and six carers said that more medical/psychiatric input would have prevented breakdown. Conclusions-There is a role for health care professionals to provide ongoing support, especially for older children with special needs.

(Arch Dis Child 1997;76:231-235)
\end{abstract}

Keywords: adoption; fostering; post-placement support.

Newcastle City Health NHS Trust, Newcastle upon Tyne

Correspondence to: Dr Joy S Holloway, Newcastle City Health NHS Trust, Division of Community Health, East Paediatric Team, Shieldfield Health Centre, 4 Clarence Walk, Newcastle upon Tyne NE2 3AN.

Accepted 29 October 1996 and from an experience of family life. In contrast, some children still in placement are seen to be unhappy and unattached.

The companion paper to this ${ }^{1}$ reports disruption in 'permanent' placements of children for adoption or long term fostering in Newce measure. Sometimes placements which break down are still positive experiences for the children or young people, ${ }^{2}$ as they may have benefited from nurturing and social training
In recent years children placed for adoption and fostering have included many older children and children with learning disabilities, emotional and behavioural problems, or medical problems. New carers may not be given sufficient information about the child they are taking into their home to meet his or her needs and to avoid their own family life being jeopardised. ${ }^{3}$ Also, when older, disturbed, or disabled children are placed, then the new carers need support after placement. ${ }^{4}$

This study asked foster and adoptive mothers for their evaluation of the success of the placement for the child and whether they had received sufficient information and support.

\section{Methods}

This is a retrospective study of a five year cohort of 234 children whose placements for permanence (adoption and long term fostering) were recommended by the family placement panel of Newcastle upon Tyne Department of Social Services from 1 January 1986 to 31 December 1990. Data obtained from the adoption and fostering unit records have been analysed and reported elsewhere. ${ }^{1}$

A previously piloted parental questionnaire was mailed to all the 234 foster and adoptive mothers of the cohort children. It was received in June 1994, three to eight years after placement. The questionnaire had 62 questions, including sections about: the start of the placement, the current situation if the child was still living with them, what had happened if the child was no longer living with them, and an overview of the placement. Two reminder letters were sent, including a phone number for people to contact the author and a reply postcard for those who wished to opt out.

If consent was obtained from the carers of school age children, the child's teacher was sent a short questionnaire about any special educational needs.

Data about the child at the time the placement was recommended by the family placement panel were extracted from files in the adoption unit for $57(53 \%)$ of the 108 respondents' children. These 57 children were not representative, but were deliberately biased towards children with special needs. This information was used to validate the questionnaire answers. Children with special needs were defined as children with special needs recorded in the family placement panel minutes or children who were said in the questionnaire to have special educational needs at placement-that is, attending special school or special unit, having extra teaching support, or 
having a statement of special educational need. Under the 1981 and 1993 Education Acts (England and Wales), children with a certain level of disability or behavioural problems can be given a 'statement of special educational need' so that appropriate resources are made available.

The data were analysed using Epi-Info 5. The Yates's corrected $\chi^{2}$ test for proportions was used or a two tailed Fisher exact test. A p value of less than 0.05 was taken as significant. Stratified analysis was used to deal with confounding factors.

\section{Results}

Of the 234 questionnaires posted, 34 (15\%) were returned by the Post Office. These did not differ significantly from the remainder in the type of placement, age, placement with birth siblings, or year of the panel's recommendation for the placement.

Of the remaining 200 questionnaires, 31 $(16 \%)$ declined to participate and 61 (31\%) did not reply at all. Thus $108(54 \%)$ responded positively and they did not differ significantly from the others for the variables type of placement, age at placement, placement with birth siblings, disruption, sex of child, special needs as identified from the panel minutes, now adopted, year of panel, or whether the child had been cared for previously by the same carers.

File records were used to validate the questionnaire replies. There was good agreement between the questionnaires and the files as to whether the child attended a special school (90\% agreement) or had a statement of special educational need ( $82 \%$ agreement). Also, $40(60 \%)$ of 67 responding mothers of children of school age gave permission for the author to write to their teacher. These teachers' responses were used to validate the parental answers about special educational need in 1994, and were in complete agreement with these.

Of the 108 responders, 56 (52\%) were boys and $52(48 \%)$ were girls. Fifty four $(50 \%)$ were placed for adoption, $43(40 \%)$ for long term fostering, and $11(10 \%)$ for long term fostering with a view to adoption. Twenty eight $(26 \%)$ were placed as a birth sibling group and 80 $(74 \%)$ were placed singly. Thirty six (33\%) were less than 1 year old when placed, 31 $(29 \%)$ were $1-6$ years old, and $41(38 \%)$ were $7-16$ years old. Thirty three $(31 \%)$ children had special needs, including educational needs (table 1). Only $56(52 \%)$ children were less than 7 and with no special needs at placement and only $36(33 \%)$ were less than 2 with no special needs.

For comparison, in January 1994 Newcastle upon Tyne had 742 of $37750(1.97 \%)$ children in special schools and $1126(2.98 \%)$ children had statements of special educational need.

OUTCOMES

Twenty five (23\%) of the 108 placements had disrupted according to the unit's records. Disruption was strongly associated with older age
Table 1 Educational needs of children in placements; values are number (\%)

\begin{tabular}{lll}
\hline & $\begin{array}{l}\text { Schooling when } \\
\text { placed (52 of } \\
\text { school age) }\end{array}$ & $\begin{array}{l}\text { Schooling now } \\
\text { (67 now of } \\
\text { school age) }\end{array}$ \\
\hline $\begin{array}{l}\text { Special school } \\
\text { Special unit in mainstream } \\
\text { school }\end{array}$ & $5(10)$ & $9(13)$ \\
$\begin{array}{l}\text { Extra teaching support } \\
\begin{array}{l}\text { Statement of special } \\
\text { educational need }\end{array}\end{array}$ & $2(4)$ & $1(1)$ \\
$\begin{array}{l}\text { Statement for learning } \\
\text { difficulty }\end{array}$ & $10(20)$ & $14(21)$ \\
$\begin{array}{l}\text { Statement for emotional } \\
\text { behavioural difficulty }\end{array}$ & $6(12)$ & $10(18)$ \\
$\begin{array}{l}\text { Statement for medical } \\
\text { problems }\end{array}$ & $4(8)$ & $7(10)$ \\
\hline
\end{tabular}

at placement. The placement of children with special needs, including educational needs, had a tendency to disruption. Twelve (36\%) of 33 children with special needs disrupted compared with $13(17 \%)$ of 75 without special needs $\quad\left(\chi^{2}=3.66, \quad p=0.056\right)$. A higher proportion of older children had these special needs, however, and if the effect of age was allowed for, the association of special needs with disruption disappeared.

In the questionnaires the mothers reported that $35(32 \%)$ children or young people were no longer living with them, having left between 10 and 21 years of age. Seventeen $(49 \%)$ of these returned to live with their birth family, eight $(23 \%)$ moved to independent living, four $(11 \%)$ returned to short term foster care, five (14\%) went into residential care, and one $(3 \%)$ to sheltered 'independent' living. In 19 (54\%) of these 35 cases the foster or adoptive mothers saw it as a breakdown. The following were most frequently cited as problems which had preceded these breakdowns: contact and attachment to birth family (13), 'acting out' behaviour (11), non-compliant behaviour (eight), not attaching (four), and problems with other children (three).

When new mothers were asked to evaluate the success of the placement for the child, 74 $(69 \%)$ said it was very successful, $13(12 \%)$ moderately successful, seven (6\%) not very successful, and eight ( $7 \%)$ not at all successful. Success was strongly associated with younger age at placement (table 2). Success was also strongly associated with adoption rather than fostering (table 3).

Outcome was analysed for special needs including the educational data. The outcome was divided into 'very successful' or a qualified response. Sixteen $(57 \%)$ of 28 special needs children had 'very successful' outcomes compared with $58(78 \%)$ of 74 children without special needs. This tendency was not statistically significant $\left(\chi^{2}=3.6, \mathrm{p}=0.058\right)$.

The mothers' assessments of the outcome for themselves were the same as for the child, except that four mothers said the placement was 'very successful' for the child, but only 'moderately successful' for themselves.

Seventy six $(70 \%)$ children were reported to have attached to their new mothers more quickly than, or about as quickly as, expected. Thirty four $(31 \%)$ attached within a week and another $15(14 \%)$ within a month. One child, 
Table 2 Mother's evaluation of the success of the placement for the child by age

\begin{tabular}{|c|c|c|c|c|}
\hline \multirow[b]{2}{*}{ Outcome for child } & \multicolumn{3}{|c|}{$\begin{array}{l}\text { Age at panel's decision to place } \\
\text { (years) }\end{array}$} & \multirow[b]{2}{*}{ Total } \\
\hline & $<1$ & $1-6$ & $7-16$ & \\
\hline \multirow{3}{*}{$\begin{array}{l}\text { Very successful } \\
\text { Moderately successful } \\
\text { Not very or not at all } \\
\text { successful }\end{array}$} & 35 & 28 & 11 & 74 \\
\hline & 1 & 2 & 10 & 13 \\
\hline & 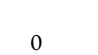 & 1 & 14 & 15 \\
\hline Total & 36 & 31 & 35 & 102 \\
\hline \multicolumn{5}{|c|}{$\chi^{2}=46.48 ; \mathrm{df}=4 ; \mathrm{p}=<0.0001$} \\
\hline \multicolumn{5}{|c|}{$\begin{array}{l}\text { Table } 3 \text { Mother's evaluation of outcome for adoption or } \\
\text { fostering }\end{array}$} \\
\hline $\begin{array}{l}\text { Outcome for } \\
\text { the child }\end{array}$ & $\begin{array}{l}\text { Long } \\
\text { term } \\
\text { fostering }\end{array}$ & $\begin{array}{l}\text { Long term } \\
\text { fostering with } \\
\text { view to adopt }\end{array}$ & Adoption & Total \\
\hline $\begin{array}{l}\text { Very successful } \\
\text { Moderately }\end{array}$ & 15 & 9 & 50 & 74 \\
\hline $\begin{array}{l}\text { successful } \\
\text { Not very or not at }\end{array}$ & 8 & 1 & 4 & 13 \\
\hline all successful & 14 & 1 & 0 & 15 \\
\hline Total & 37 & 11 & 54 & 102 \\
\hline
\end{tabular}

however, took over a year to attach and 14 $(13 \%)$ had never attached. Three of these unattached children were still living with the new family and they had only been $5-7$ years old at placement.

Seventy three $(68 \%)$ respondents still had the children living with them. In an overview of how things had turned out, medical problems were reported to be worse than expected by only three $(4 \%)$ carers. Learning difficulties were worse for $11(15 \%)$, and $12(16 \%)$ new carers had found emotional or behavioural difficulties worse, or much worse, than expected.

Thirty nine $(36 \%)$ adoptive or foster mothers said they had experienced major difficulties in the placement. Reporting major difficulties was very strongly associated with increased age at placement $\left(\chi^{2}=38.62 ; \mathrm{df}=2 ; \mathrm{p}<0.0001\right)$, with only one $(3 \%)$ of 36 infant placements having had major difficulties, whereas 15 $(48 \%)$ of 31 children aged $1-6$ years and 23 $(56 \%)$ of 41 children placed when older than 6 years old had had major difficulties.

In an open question on the cause of most stress in the placement, the most common answers were: confrontational behaviour, noncompliance (18); 'acting out', lying, stealing, aggression, destructiveness, etc (16); contact with birth family (16); school problems, mainly behavioural (16); legal delays and uncertainties (16); medical problems (6); problems with other children in the house (5); not attaching (4); and severe marital stress related to the placement (2).

Only two mothers said the pleasure they experienced in the placement now was 'less or much less than expected'. Forty nine said the pleasure was 'greater than expected'. Mothers said the cause of most pleasure was: being able to have the child, bonding to him or her (37); the child's emotional, social, or personal progress, character development (36); the child attaching to the parents and loving them (26); being a family (24); watching the child learn things, develop skills (15); and fun and shared activity (12).

SERVICES

There was a small group of respondents who were very dissatisfied with the transfer of information at placement. Six $(6 \%)$ of the mothers said they had inaccurate medical information and $17(16 \%)$ said it was insufficient. Fourteen $(13 \%)$ said they had inaccurate information on emotional or behavioural difficulties and 21 $(19 \%)$ said it was insufficient. Eight $(7 \%)$ said they had inaccurate information on learning difficulties and $13(12 \%)$ said it was insufficient.

With regard to medical information, six of the dissatisfied respondents wished they had been given a full medical history, including minor childhood illnesses and routine health surveillance data. Five more would have liked better information about existing medical problems - for example, epilepsy, asthma, eczema, neurological disease, or sequelae from sexual abuse. Two responders specifically wanted more information on hereditary disorders in the birth family. Matters which the carers said they were not told about included hyperactivity, previous psychiatric involvement, the extent of previous abuse, unexplained bruising, and a squint.

Twenty two $(20 \%)$ said that the severity of emotional and behavioural difficulties when the child was placed was worse or much worse than expected. Twenty six (24\%) said that the time these problems lasted was worse or much worse than expected. None of these children was less than 1 year old when placed, but 11 were aged only 1-6 years at placement. Seven children had problems which lasted much longer than expected.

Twelve (11\%) new mothers said they did not have enough support in the first six months. Eight $(11 \%)$ of 73 said they do not have enough support now. Twenty one (19\%) said that more medical, psychological, or psychiatric input would have relieved stress. When asked what help they would have liked, they replied psychiatrist (five), psychologist (six), and speech therapist (one); nine mentioned other wishes including someone to talk to and advice over sexual issues. Six of 19 (32\%) said that more medical, psychological, or psychiatric help would have prevented breakdown.

There was no association between the transfer of information on medical problems or learning difficulties and outcome, but the parents who said they were not told enough about emotional and behavioural problems rated the placement as less successful $\left(\chi^{2}=16.11, \mathrm{df}=2\right.$, $\mathrm{p}=0.0003$ ).

The mothers were asked to record which heath professionals they had seen and how helpful they had been (table 4) and similarly for other people (table 5). When asked to state the most helpful people in the first six months, health visitors (30) and general practitioners (25) came top of the health professionals list. Family and friends (24), the child's social worker (19), and the adoption unit social 
Table 4 Health professionals found to be helpful or very helpful; values are number (\%)

\begin{tabular}{lll}
\hline & At first $(n=108)$ & Now $(n=73)$ \\
\hline General practitioner & $56(52)$ & $49(67)$ \\
Health visitor & $41(38)$ & $6(8)$ \\
Community doctor & $20(19)$ & $5(7)$ \\
School doctor & $14(13)$ & $19(26)$ \\
School nurse & $13(12)$ & $21(29)$ \\
Hospital paediatrician & $13(12)$ & $11(15)$ \\
Physiotherapist & $4(4)$ & $6(8)$ \\
Psychiatrist & $4(4)$ & 0 \\
Speech therapist & $5(5)$ & $5(7)$ \\
\hline
\end{tabular}

Table 5 Other people found to be helpful or very helpful; values are number (\%)

\begin{tabular}{lll}
\hline & At first $(n=108)$ & Now (n=73) \\
\hline Family and friends & $97(90)$ & $66(90)$ \\
Adoption social worker & $88(81)$ & $8(11)$ \\
Child's social worker & $79(73)$ & $5(7)$ \\
Other foster parents & $46(43)$ & $31(42)$ \\
Teacher & $42(39)$ & $56(77)$ \\
Church & $24(22)$ & $21(29)$ \\
Educational psychologist & $4(4)$ & $7(10)$ \\
\hline
\end{tabular}

worker (18) were the most helpful of other people.

Currently, the most helpful health professional was the general practitioner (44), whereas family and friends (24) and teachers (16) were the current most helpful non-health professionals.

Community doctors, school doctors, school nurses, and hospital paediatricians were the next most frequently cited as being helpful health professionals, whereas other foster and adoptive parents and churches were the next most frequently cited sources of help outside the health professions.

\section{Discussion}

The response rate to the postal questionnaire of $54 \%$ was lower than hoped for, but was comparable with some other studies ${ }^{5}$ and the respondents did not differ significantly from the non-respondents, so it is unlikely that the sample was seriously misrepresentative. A postal questionnaire has limitations for collecting such sensitive information, but the respondents were often very frank. As well as answering the questions they often volunteered extra information by letter or phone call. Nevertheless, some of the non-respondents may have been put off by a postal approach.

OUTCOMES

It is not easy to say that the placement of a child in your family has been only 'moderately successful' for him or her. In fact, $69 \%$ of the placements of children older than 6 years old had a qualified evaluation (that is 'moderately', 'not very', or 'not at all' successful), which is discouraging. Almost all (97\%) the placements of infants and most $(90 \%)$ of the placements of 1-6 year olds were rated as 'very successful'. This may be because children placed at a younger age are easier to care for, or it may be that families experience more problems as children grow older and that these infant placements will experience more difficulties in the next 5-10 years. By then, however, the children will have had those years to settle and to attach.
The new carers made their evaluations after three to eight years of placement. They used their own criteria for success. Other people may have evaluated the placements differently. These are the people who know the child best, however. It would also be interesting to know how many mothers of older children in intact families feel that the family situation for their child is only 'moderately successful' or even 'not at all successful'. However, the study children had been removed from 'unsuccessful' circumstances and the aim was to provide them with 'very successful' placements in better than average families.

Although $93 \%$ of adoptive placements were 'very successful' compared with $41 \%$ of fostering placements, this appears to be due to the confounding factor of age, as does the tendency for special needs children (including educational special needs) to have a less 'successful' outcome. Age at placement is the most powerful factor for predicting the new carer's evaluation of the success of the placement for the child. A total of $94 \%$ of children less than 6 years old were rated 'very successful' compared with only $31 \%$ of children older than 6 years.

Although only one mother with whom an infant had been placed had experienced major difficulties, roughly half of all the other mothers reported major difficulties and these were spread across all ages over 1 year. Placing young children may result in major difficulties in spite of being rated 'very successful'. Of course, many intact families experience stress and major difficulties, but these figures seem considerably higher than expected. The foster or adoptive mothers' causes of stress were mainly behavioural problems, followed by contact with the birth family and legal delays. Although social workers could help in all these areas, there is also a role for health professionals in supporting these families.

Although most children attached quickly to their new mothers, it is disturbing that three young children were described as 'unattached' at least three years into their placement. In fact, one young child was still in a five year long placement which was rated as 'not at all successful' by the carer. About a quarter of the children had taken longer to attach than expected.

Seventeen of the 35 children who had left the new carer's home returned to their birth family. Although in some cases this was seen as positive, in 13 placements contact with, and attachment to, the birth family were cited as causing a breakdown. This raises the question as to whether these children could have remained with their birth family with support from the start or, having decided to remove them from the birth family, whether contact should have been managed differently.

Thirty one per cent of children had special needs at the time of placement, when educational data were added to the note of special needs found in the minutes of the family placement panel. This shows that the children placed for permanence were a vulnerable group. Twenty per cent of school children 
placed had statements of special education need compared with only about $3 \%$ in the Newcastle school population. These children not only had medical, behavioural, or educational problems, but they also had been separated from their birth families and often had a history of abuse or neglect. Although vulnerable in many ways, the tendency for special needs to be associated with disruption could be explained by the effect of age.

A substantial number of carers said that learning difficulties (15\%) or behavioural problems $(16 \%)$ were worse or much worse now than expected. This shows the importance of preparing prospective adoptive and foster parents so that their expectations are realistic.

SERVICES

It is disappointing that 17 new carers said that they had received insufficient medical information about their child, as much time is spent by medical advisers collecting medical information. The transfer of this information has now been improved.

Dissatisfaction was greatest about the information given on emotional and behavioural difficulties and this was associated with a worse outcome. This may have been due to the poor transfer of information, or even to intentional understatement, as some carers alleged. Certainly the examination of a sample of children's files found a poor match between recorded behavioural problems and what new carers said they were told. Although this may reflect recall bias, some behavioural problems may have to be experienced for a true appreciation of their severity. Carers frequently said that the most accurate information about a child's behaviour came from the previous foster carer.

At least a third of children aged 1-6 years at placement had behavioural problems lasting longer than expected. Behavioural problems in young children must not be discounted.

Twenty one carers would have liked more medical, psychological, or psychiatric input. This highlights the need for more support after placement, as do the six carers who said that more of this input would have prevented the breakdown. Families caring for traumatised youngsters need extra support.

General practitioners, health visitors, and community child health doctors were most frequently cited as helpful in the first six months. Between them these health professionals are in contact with most children placed for adoption or long term fostering, so they have a role to offer in providing support. Some special needs children also had support from hospital paediatricians and psychiatrists. Later in placement the school health team was frequently cited, and 11 children still had the support of a hospital paediatrician.

Family and friends were important throughout, but although social workers were helpful at first, they were not usually involved later on. Teachers and other foster and adoptive parents were seen to be helpful, particularly later in the placement, as was the family's church. The March 1996 consultation paper on the proposed adoption bill talks about post-adoption services, but such services need resources. There are moves to develop support from the social services after placement, ${ }^{6}$ but while social workers continue to withdraw from families after placement, it is important that health professional and other support systems are maintained. General practitioners, health visitors, the school health team, and paediatricians all have the opportunity to offer support after placement.

\section{Recommendations}

(1) Accurate and full written information about medical problems, emotional and behavioural problems, or learning difficulties should be provided to the new carer before the children are placed. The new carers should meet the previous foster carers, paediatricians, or teachers when appropriate.

(2) Primary health care professionals and community health professionals should be made more aware of the needs of adoptive and foster families and their children so that they can offer support in normal consultations.

(3) Specialist support should be provided after placement, where appropriate, by social workers, paediatricians, psychiatrists, or psychologists.

I should like to thank Dr Hans Steiner, Dr Louise Parker, $\mathrm{Mr}$ I should like to thank Dr Hans Steiner, Dr Louise Parker, Mr stages of this study, also the adoptive and foster mothers who stages of this study, also the adoptive and foster mothers who
responded and the staff at Ravenswood Clinic and the Adoption Unit, in Newcastle upon Tyne.

1 Holloway JS. Outcome in placements for adoption or long term fostering. Arch Dis Child 1997;76:227-30

2 Triseliotis J. Foster-care outcomes: a review of key research findings. Adoption and Fostering 1989;13.3:5-17.

3 Yates P. Post-placement support for adoptive families of hard to place children [dissertation]. Edinburgh: University of Edinburgh, 1985

4 Thoburn J, Murdoch A, O'Brien A. Permanence in child care. Oxford: Blackwell, 1987.

5 Borland M, O'Hara G, Triseliotis J. Permanency, planning and disruption in the Lothian Region. The outcome of permanent family placements in two Scottish local authorities. permanent family placements in two Scottish local authorit

6 Wassell S. Training in post-placement support. In: Phillips R, McWilliam E, eds. After adoption - working with adoptive families. London: BAAF, 1996. 